\title{
INSTITUCIONALIZAÇÃO DA INFÂNCIA DESVALIDA EM PERSPECTIVA COMPARADA LISBOA/PORTUGAL - FLORIANO/PIAUÍ/BRASIL (1834-1890)
}

\author{
INSTITUCIONALIZACIÓN DE LA INFANCIA DISCAPACITADA EN UNA \\ PERSPECTIVA COMPARTIDA LISBOA / PORTUGAL - FLORIANO/PIAUÍ/BRASIL \\ (1834-1890)
}

INSTITUTIONALIZATION OF DISABLED CHILDHOOD IN A COMPARED PERSPECTIVE LISBON / PORTUGAL - FLORIANO/PIAUÍ/BRAZIL (1834-1890)

\author{
Thatianny Jasmine Castro Martins de CARVALHO ${ }^{1}$ \\ Patrícia Helena de Carvalho HOLANDA ${ }^{2}$
}

RESUMO: Este trabalho tem como objetivos identificar as relações de causalidade, confluências e divergências entre os contextos de criação das instituições asilares; analisar estatutos, missões, orçamentos das despesas e demais fontes documentais como ofícios e relatórios, que evidenciem os vínculos de identidade e circulação de ideias sobre o tema. Para atender profundas mudanças sociais percebidas mais intensamente na segunda metade do século XIX, em diferentes contextos, foram implantadas instituições de acolhimento à infância desvalida em Portugal e, em seguida, sob influência do processo colonizador e avanço do capitalismo industrial e da globalização, também no Brasil. Esta pesquisa pretende tecer diálogos entre instituições de acolhimento de Lisboa/Portugal e Floriano/Piauí/Brasil. Resultados parciais revelam diferenças, aproximações e a circulação de ideias sobre a infância desvalida aquém e além-mar. O estudo apoia-se em autores como Nóvoa (2009), Rizzini (1997), Newitt (2018), Venâncio (1997), entre outros.

PALAVRAS-CHAVE: Infância desvalida. Portugal. Brasil. Asilo.

RESUMEN: Este trabajo pretende identificar las relaciones de causalidad, las confluencias y las divergencias entre los contextos de creación de las instituciones de asilo; analizar los estatutos, las misiones, los presupuestos de gastos y otras fuentes documentales como cartas e informes, que muestran los vínculos de identidad y circulación de ideas sobre el tema. Para hacer frente a los profundos cambios sociales percibidos con mayor intensidad en la segunda mitad del siglo XIX, se crearon, en diferentes contextos, instituciones para acoger a los niños desfavorecidos en Portugal y luego, bajo la influencia del proceso colonizador y el avance del capitalismo industrial y la globalización, también en Brasil. Esta investigación pretende tejer diálogos entre instituciones de acogida en Lisboa/Portugal y Floriano/Piauí/Brasil. Los resultados parciales revelan diferencias, aproximaciones y la circulación de ideas sobre los

\footnotetext{
${ }^{1}$ Universidade Federal do Piauí (UFPI), Picos - PI - Brasil. Professora Assistente vinculada à Coordenação de Pedagogia. Doutoranda no Programa de Pós-Graduação em Educação Brasileira (UFC). ORCID: https://orcid.org/0000-0002-3375-8366. E-mail: jasmine-14_4@hotmail.com

${ }^{2}$ Universidade Federal do Ceará (UFC), Fortaleza - CE - Brasil. Professora Titular vinculada ao Departamento de Fundamentos da Educação. Doutorado em Educação (UFC). ORCID: https://orcid.org/0000-0002-8233-1190. E-mail: profa.patriciaholanda@gmail.com
}

RIAEE - Revista Ibero-Americana de Estudos em Educação, Araraquara, v. 16, n. 3, p. 1774-1790, jul./set. 2021. e-ISSN: 1982-5587 DOI: https://doi.org/10.21723/riaee.v16i3.13649 
niños desfavorecidos aquí y en el extranjero. El estudio se basa en autores como Nóvoa (2009), Rizzini (1997), Newitt (2018), Venâncio (1997), entre otros.

PALABRAS CLAVE: Infancia desfavorecida. Portugal. Brasil. Asilo.

ABSTRACT: This paper aims to identify causal relationships, confluences and divergences between the creation contexts of the asylum institutions; analyze statutes, missions, expenditure budgets and other documentary sources such as letters and reports that show relationships of identity and circulation of ideas on the topic. In order to attend to profound social changes perceived more intensely in the second half of the 19th century, in different contexts, institutions for the care of deprived children were established in Portugal and, subsequently, under the influence of the colonizing process and the advance of industrial capitalism and globalization, also in the Brazil. This research intends to weave dialogues and comparative grids between host institutions in Lisbon / Portugal and Floriano / Piaui / Brazil. Partial results reveal differences, approximations and the circulation of ideas about disadvantaged children below and beyond. The study is supported by authors such as Nóvoa (2009), Rizzini (1997), Newitt (2018), Venâncio (1997), among others.

KEYWORDS: Childhood deprived. Portugal. Brazil. Asylum.

\title{
Introdução
}

\begin{abstract}
"Entendendo por desvalidos aqueles que nada valem, foi com este nome que abriram as primeiras casas de asilo destinadas às crianças. Como o nome sugere, estas nada valiam, logo, não era necessário grande empenho na sua educação e formação, bastava dar-lhes alimentação (nem sempre a melhor, em qualidade e quantidade) e tirá-las das ruas, tentando esconder a sua existência. Era preciso afastá-las do convívio com os demais cidadãos", (Franco, 2018, p. 75).
\end{abstract}

Esta investigação é originária de uma pesquisa mais ampla, tema de doutoramento sobre Instituições de Infância Desvalida em Perspectiva Comparada Brasil-Portugal-Angola, com recorte temporal mais abrangente. Esta produção, que se situa em contexto de aproximação das duas espacialidades Lisboa/Portugal e Floriano/Piauí/Brasil, entre os anos de 1834 e 1890, objetiva identificar relações de causalidade, confluências e divergências entre os contextos de criação das instituições asilares; analisar estatutos, missões, orçamentos das despesas e demais fontes documentais como ofícios e relatórios, que evidenciem relações de identidade e circulação de ideias sobre o tema.

Instituições asilares foram implantadas em Portugal no fim do século XVIII, no reinado de D. Maria I, e, de forma semelhante, outros asilos e colônias foram instalados na maioria dos estados brasileiros, no início da Primeira República, na virada dos séculos XIX e $\mathrm{XX}$, evidenciando um caráter fortemente caritativo, enquanto outras iniciativas de natureza 
estatal começavam a ganhar corpo, ainda que de maneira tímida em face das necessidades sociais de assistência.

A partir de características observacionais e explicativas dos padrões e lógicas da história e sociabilidade local, esta investigação pretende revelar concepções e trajetórias que podem vir a ser semelhantes ou diferentes, dentro de uma lógica de assistência posta numa teia complexa de relações interinstitucionais, práticas culturais e políticas de construção republicana modelada na experiência europeia.

A pesquisa caracteriza-se como qualitativa, articulando abordagens e métodos da pesquisa comparativa à pesquisa histórica/historiográfica e sociológica. Utilizar-se-á o modelo de Bereday (1964) para a condução de estudos comparados, com fases específicas de descrição (dados observáveis), interpretação (evolução dos dados), justaposição (estabelecendo semelhanças e diferenças) e comparação (hipóteses). Como referencial metodológico de Educação Comparada, apoiamo-nos em Cavalcante (2008), Bray, Adamson e Mason (2015), Nóvoa (2009), entre outros.

Sobre as instituições portuguesas, selecionamos fontes documentais adquiridas em pesquisa na Biblioteca Nacional de Portugal, durante o mês de novembro de 2019. Sobre as instituições asilares que atendiam à Infância Desvalida no período supramencionado, denominados: a) "Mappa Demonstrativo da Receita e Despeza, e do Movimento e Frequência dos Alumnos Matriculados nas Casas de Asylo da Infância Desvalida de Lisboa - desde a sua fundação, em 1834, até 31 de dezembro de 1871"; b) "Notícia sobre a instituição das casas de asylo da infância desvalida de Lisboa: seu progressivo desenvolvimento e estado atual", publicado pela Imprensa Nacional em 1875; c) “Conta da Receita e Despeza da Sociedade das Casas de Asylo da Infância Desvalida de Lisboa", relativa ao ano de 1889; "Regulamentos, Relatório e Contas da Sociedade de Beneficência para as Cazas de Asilo da Primeira Infância Desvalida no anno de 1834".

No tocante ao Piauí, selecionamos fontes primárias adquiridas em pesquisa na Sala do Poder Executivo (SPE) do Arquivo Público do Piauí, durante o mês de outubro de 2019. Sobre instituições asilares que atendiam à Infância Desvalida durante o século XIX, utilizaremos nesta análise: “Orçamento das Despesas do Estabelecimento Rural de São Pedro de Alcântara, para o trimestre de outubro a dezembro deste anno, exercício de 1876-1877”; "Mappa dos Alumnos que frequentaram a escola de Primeiras Lettras do Estabelecimento Rural de São Pedro de Alcântara", de agosto de 1874 a dezembro de 1875; "Serviços em andamento no Estabelecimento Rural de São Pedro de Alcântara”, no ano de 1876; Ofícios $n^{\circ} 9$ e $n^{\circ} 299$, dos meses de abril e setembro, respectivamente, do ano de 1876; Carta datada

RIAEE - Revista Ibero-Americana de Estudos em Educação, Araraquara, v. 16, n. 3, p. 1774-1790, jul./set. 2021. e-ISSN: 1982-5587 DOI: https://doi.org/10.21723/riaee.v16i3.13649 
de 31 de agosto de 1876 com pedido de mãe ao estabelecimento para devolução da filha "liberta nacional"; e, por fim, o Oficio $n^{\circ} 67$ de 20 de março de 1876, assinado pelo Presidente da Província e encaminhado ao Diretor do Estabelecimento.

É imperioso destacar que esta pesquisa se encontra em fase de construção, com resultados parciais e ainda sem conclusões, tendo em vista que, para esta produção, fizeram-se primeiras aproximações das fontes nas duas espacialidades, com necessário cuidado de proporcionalidade e critérios comparativos precisos, mas com vista a aprofundamentos analíticos posteriores.

Este trabalho está dividido em quatro seções, a saber: a) Instituições de Infância Desvalida em Portugal-Brasil, em que há um esboço de contextualização e historicidade das casas asilares e assistenciais, inicialmente em Portugal, com destaque para a circulação das ideias e influência do colonialismo português na implantação destas instituições no Brasil; b) Estabelecimento Rural São Pedro de Alcântara, município de Floriano/Piauí/Brasil: asilo piauiense de formação agrícola; c) Casa Pia de Lisboa: nascedouro da institucionalização da infância desvalida em Portugal; d) Resultados comparativos parciais.

\section{Instituições de Infância Desvalida em Portugal-Brasil}

“A solução lógica é impedir que 'essa lama das cidades' se forme, é disciplinar, dirigir a concentração das gentes nos centros urbanos, por meio de medidas proibitivas da instalação de quem não tem emprego fixo, ou não der trabalho que seja necessário. [...] A assistência à criança abandonada ou desvalida, deve fazer-se no sentido de promover a sua fixação no meio rural, afastando-a das cidades onde é enorme a concentração de gente humilde, sem facilidade de angariar meios de vida" (Garrett, 1940, p. 357).

Almeida Garrett, além de escritor e dramaturgo romântico, foi ministro e secretário de estado honorário português e presidiu a Junta Geral do Distrito do Porto, que, à época da publicação do excerto acima, denominava-se Junta de Província do Douro Litoral. Quando de sua administração da Junta Geral, esta era responsável por manter, fiscalizar e gerir nove instituições asilares de infância desvalida. A primeira delas foi o Hospício-Materno, que recebia crianças com menos de um ano de idade, em situação de aleitamento; em seguida, estas eram transferidas para uma Casa-Hospício, quando já podiam fazer uma alimentação mista, até chegarem à idade escolar, sendo encaminhados para outras instituições - como internatos e colônias industriais e agrícolas, por exemplo -, que lhes revelassem aptidões especiais para determinado ensino ou instrução profissional.

Essas instituições que, desde o fim do século XVIII, cresciam em Portugal - as 
primeiras instaladas em Lisboa, Porto, Coimbra e Braga - e, até a metade do século XIX, em todo o país, tinham como missão oferecer proteção, vivência familiar e cristã, que complementassem a função das rodas e dos hospícios. No que diz respeito à filantropia da "infância desvalida", importa considerar que esta denominação foi utilizada, inicialmente, pelas primeiras instituições de acolhimento e asilo, do tipo carcerário, que recebiam e designavam delinquentes, vadios, desobedientes, incorrigíveis, abandonados, filhos ilegítimos ou de cônjuges separados ou sem renda fixa. "Desvalidas" porque "sem valor", num contexto de crescente urbanização e transformações sociais e econômicas que levavam à mendicidade e ao abandono de crianças. Estas instituições pretendiam, em linhas gerais, oferecer proteção, alimentação e instrução básica que transformassem a criança na "grande, segura e risonha esperança do dia de amanhã" (GARRETT, 1830, p. 5). Acerca disso, Geremek (1995, p. 197) preconiza que essa política de grande enclausuramento marcou profundamente a evolução das sociedades modernas. Esta era a política praticada nas casas assistenciais. O enclausuramento era a realidade defendida, até esse período.

Desde o final do século XIX, com a constituição do modelo Estado-nação, a despeito das transformações socioeconômicas, políticas e étnicas alavancadas pela globalização e pelo fenômeno mundial de consolidação do capitalismo e a consequente reorganização dos espaços urbanos face às novas necessidades culturais, Portugal e Brasil - por pertencerem à mesma comunidade linguística, possuírem relações históricas e culturais de longa duração, partilhamento de identidades culturais pela via do processo colonizador - ensejam e estimulam o desenvolvimento de estudos histórico-comparativos sobre instituições educativas e circulação de ideias de proteção, assistência e educação àqueles que se encontram à margem da evolução social, tantas vezes esquecidos pela história oficial. Quanto a esses propósitos comparativos, Nóvoa (2000, p. 127) preconiza:

[...] todas as comunidades são imaginadas e distinguem-se, não por uma eventual falsidade/autenticidade, mas justamente pelos modos como se imaginam. Eis o que conduz o comparatismo a virar-se para novas realidades, que não cabem nas geografias nacionais.

Essas instituições do tipo internato caracterizavam-se em dois tipos: 1) Educacionais (ou escolares) quando significavam formação específica ou direcionamento dos estudos, a exemplo dos colégios internos, institutos militares, seminários, academias, entre outras; 2) Assistenciais de proteção e acolhimento, como institutos, instituições de solidariedade social, orfanatos, asilos, lares de acolhimento etc. Entretanto, através das fontes documentais em análise, percebe-se que as casas do tipo asilo nomeiam grande número de instituições de 
assistência à infância desvalida, onde estas assumem função de proteção, assistência, acolhimento e educação.

No Brasil Colônia, a fim de solucionar o problema de abandono dos órfãos, crianças pobres, afastadas do caminho da salvação, os jesuítas, objetivando o resgate de almas com comportamentos desviantes dos valores cristãos, criaram os colégios de meninos, "instituições destinadas a abrigar legiões de indiozinhos sem pai”(DEL PRIORE, 1991, p. 27).

O período colonial apresentou diferentes ritmos de crescimento e, nos primeiros dois séculos, com o crescimento acelerado das cidades e pelas consequentes transformações sociais e estruturais, aumentou o índice de crianças abandonadas ou sem habitação. Alguns “enjeitados" acabavam sendo adotados como "filhos de criação" ou agregados por famílias estruturadas (VENÂNCIO, 1997, p. 190).

Foi determinado a Antônio Paes Sandi, Governador da Capitania do Rio de Janeiro, através de uma carta régia de 1693, que os expostos fossem criados com o custeio do poder público. Somente em 1738 criou-se a Roda dos Expostos no Rio de Janeiro, com a doação de Romão de Mattos Duarte, com o objetivo de servir de amparo aos recém-nascidos abandonados. "Casa de Expostos", "Depósito de Expostos" e "Casa de Roda" foram algumas das denominações dadas às instituições que utilizaram a roda para receber as crianças e os adolescentes pobres abandonados (PAVÃO, 2011).

Até o fim do Império, as medidas de amparo à infância pobre no Brasil assumiam um caráter religioso, vinculadas, na maioria das vezes, à Igreja Católica. As primeiras instituições de atendimento à infância desvalida apareceram no Brasil na segunda metade do século XIX, como o Imperial Instituto de Meninos Cegos (1854), o Imperial Instituto de Meninos Surdos (1855), a Escola de Aprendiz de Marinheiro (1873), o Asilo de Meninos Desvalidos, a Escola Quinze de Novembro (1889), dentre outras.

Essas primeiras instituições tinham o propósito de auxiliar crianças desvalidas e orientar a maternidade com princípios da puericultura, num processo de desenvolvimento civilizatório e fortalecimento das gerações e da raça humana. Com o avanço da ciência médica, sobretudo em decorrência da preocupação com as causas da mortalidade infantil e o avanço de doenças infectocontagiosas, articulada aos processos de reformas urbanas, práticas médicas higienistas e eugenistas, estiveram na vanguarda da criação de instituições, influenciando políticas de assistência à infância pobre no Brasil. Esse pensamento tinha como finalidade a prevenção da desordem, da criminalidade e da loucura.

As primeiras instituições articulavam medicina social, filantropia e ações governamentais e foram reconhecidas como Roda de Expostos, Hospitais, Casas de 
Recolhimento e Colégios de Órfãos, muitas vezes com administração privada e auxílio financeiro do governo da província.

\section{Estabelecimento Rural São Pedro de Alcântara, município de Floriano/Piauí/Brasil: asilo piauiense de formação agrícola}

Fundado em 1873, na província do Piauí, pelo decreto n. 5.392, de 10 de setembro de 1873, como escola de agricultura prática, com nome oficial Estabelecimento das Fazendas Nacionais do Piaú, o Estabelecimento Rural São Pedro de Alcântara, no município de Floriano, foi uma das primeiras instituições asilares com atendimento à infância desvalida no Piauí. Atualmente, é denominada Colégio Agrícola de São Pedro de Alcântara, com localização na Avenida Esmeraldo de Freitas, s/n, Floriano, Piauí.

O Estabelecimento Rural São Pedro de Alcântara (ERSA) pode ser considerado casa asilar, tendo em vista que, segundo o relatório da Secretaria de Estado dos Negócios da Agricultura, Comércio e Obras Públicas, apresentado à Assembleia Geral Legislativa, o contrato teria duas vantagens principais: desoneraria o Estado das despesas com a manutenção das fazendas, que pouco produziam pela falta de conhecimento de seus administradores, e facilitaria o emprego de libertos e a educação de seus filhos (BRASIL, 1874, p. 16).

Tal preocupação remete à promulgação da Lei do Ventre Livre, promulgada em 1871, que libertou os nascituros, regulou a manumissão dos cativos e atribuiu ao Estado a obrigação de cuidar dos ingênuos após os oito anos de idade. Desse modo, a criação de instituições para abrigar os libertos tornou-se uma política do governo imperial (LIMA, 1988, p. 120).

Com o uso atual de Centro de Referência de Assistência Social, o Estabelecimento Rural São Pedro de Alcântara e a Fábrica de Laticínios pertenciam às antigas Fazendas Nacionais do Piauí que, originalmente, eram grandes extensões de terras doadas aos primeiros desbravadores, no Brasil Colônia. Mais tarde, passaram a pertencer à Companhia de Jesus e, quando da expulsão dos jesuítas por Marquês de Pombal, em 1759, as terras foram incorporadas à Coroa Portuguesa até o fim do período imperial. Com a República, as Fazendas Nacionais ficaram em poder da União, que arrendou ou vendeu parte das terras, que deram origem a vários municípios no atual estado do Piauí.

O Estabelecimento Rural São Pedro de Alcântara, em Floriano, é um importante testemunho da ocupação do interior do Brasil durante os séculos XVIII e XIX. Com imagem recente da instituição, é possível visualizar suas características de arquitetura externa: 
Figura 1 - Fachada recente do prédio onde funcionou o Estabelecimento Rural São Pedro de Alcântara

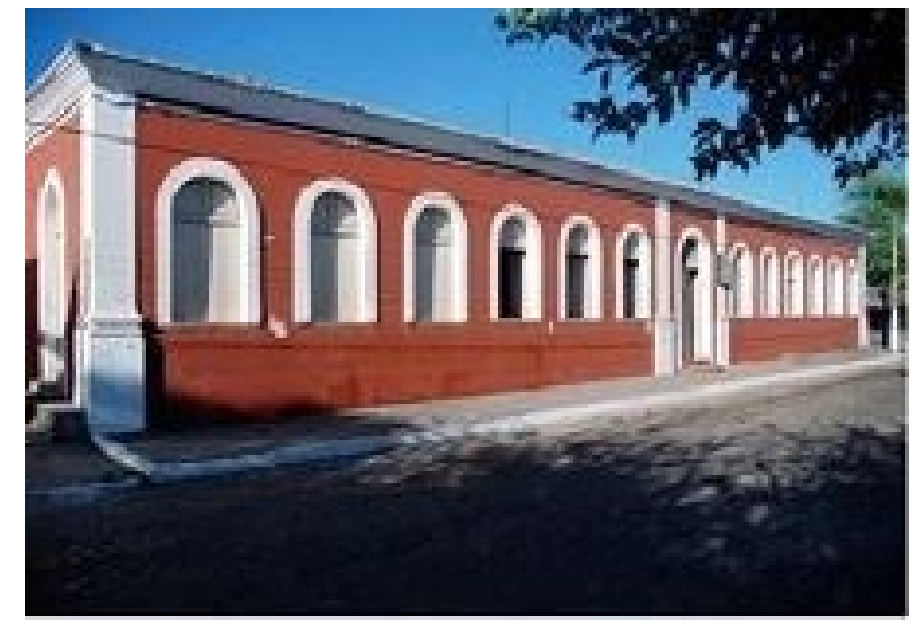

Fonte: Google imagens ${ }^{3}$

Nas fontes documentais que sustentam este trabalho, o oficio número 13 de 27 de junho de 1876, encaminhado ao Presidente da Província do Piauí e assinado pelo Diretor Interino da instituição Dr. Antônio Rodrigues da Silveira, informa que este assumiu a diretoria do estabelecimento, tendo em vista a morte do então diretor Dr. Francisco Parente, ocorrida no dia 16 do corrente mês na cidade de Amarante. Na qualidade de escripturário do mesmo e na ausência de um vice-diretor, Dr. Antônio Rodrigues da Silveira assumiu a gestão da instituição, informando, neste ofício, a conservação e andamento dos serviços já encaminhados pelo ex-diretor, como a construção do prédio de residência.

Em ofício $\mathrm{n}^{\mathrm{o}} 135$ de 17 de outubro de 1876, o Procurador Fiscal Bolívar Mendes escreveu ao Inspector (sem nome, no referido documento) do ERSPA mencionando achar conveniente que o Diretor Interino da "Colônia São Pedro de Alcântara" tomasse providências tanto em relação aos libertos que fossem residir nas terras das fazendas sujeitas à sua administração, quanto aos que fossem residir nas que se acham "sob a imediata administração desta tesouraria", que deveriam ficar "sujeitos às condições já impostas ou que se julgar útil estabelecer, ou não serão admitidos como agregados das ditas fazendas”.

Subentende-se desta escritura que há regras claras e condições para admissão dos libertos nacionais, num contexto em que as fronteiras entre liberdade e escravidão são tênues na sociedade escravista oitocentista, tornando ambíguas as experiências de trabalhadores escravos, libertos e livres pobres.

${ }^{3}$ Disponível em: http:/www.ipatrimonio.org/floriano-estabelecimento-rural-sao-pedro-dealcantara/\#!/map=38329\&loc=-23.529838338920804,-406.65764808654785,13 Acesso em: 02 de maio de 2020. 
Tais regras e condições anunciadas acima são expostas no Ofício $n^{\circ}$ 299, de 29 de abril de 1876, intitulado "Informe ao Sr. Inspetor" sobre regras de admissão e moradias dos jovens libertos nacionais. Como é possível perceber no excerto abaixo:

E como seja de alta conveniência dos serviços d'este estabelecimento, que os ditos libertos não continuem a morar nas terras da nação sem pagar em certo tributo, ou de obrigarem a prestar anualmente 30 dias de serviço grátis a este estabelecimento ou à fazenda onde residirem [...]. Sendo obrigados da mesma forma os agregados livres.

É importante destacar que a institucionalização de crianças, jovens e adultos no Estabelecimento Rural São Pedro de Alcântara tem a função de abrigar pessoas desligadas da jurisdição do governo, de acordo com a Lei de 28 de setembro de 1871, que preconiza a moradia livre destes nas fazendas nacionais, sem outro ônus, "sem viverem ociosamente, furtando e causando toda sorte de males de que são capazes”, conforme trecho final do "Informe ao Sr. Inspetor":

Figura 2 - Ofício no 299 , de 29 de abril de 1876

Fonte: Acervo das autoras

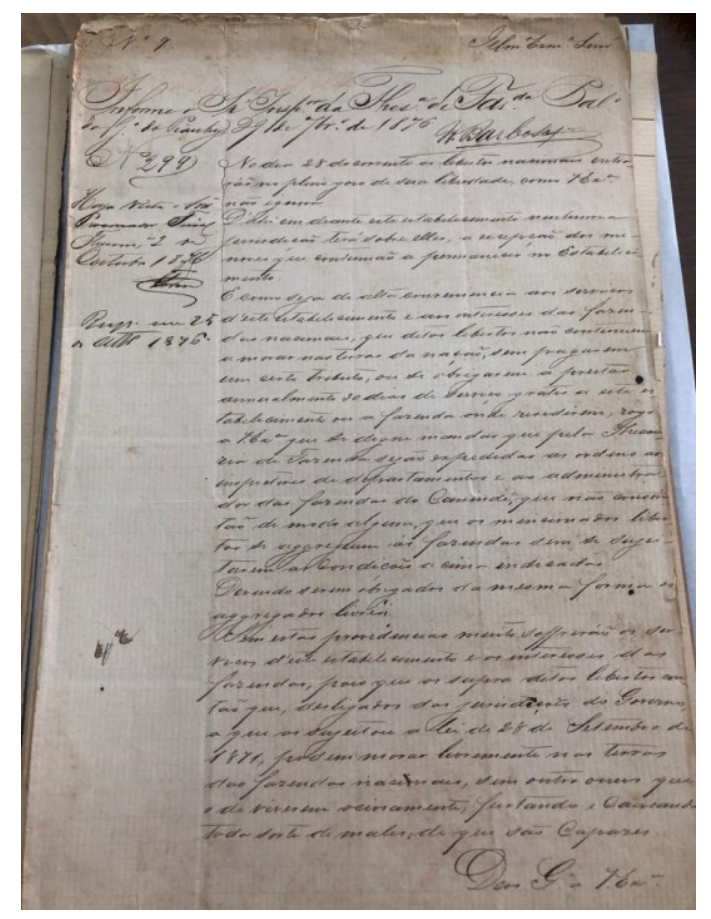

Nestas e demais fontes do poder público sobre o ERSPA, observadas até o momento, percebe-se a obrigatoriedade do trabalho como pagamento pela moradia e saída da marginalidade decorrente do ócio. Nesse período, no Brasil, assim como em Cuba e nos Estados Unidos, manteve-se a escravidão como meio de exploração do trabalho, ao longo do 
século XIX, de uma forma diferente da escravidão anterior. O capitalismo industrial consolidou-se como um novo sistema que se beneficia dessa "segunda escravidão", por exemplo, no ciclo do café, no Brasil.

Nesse contexto, as instituições de caridade e filantropia assumem também uma função de controle da pobreza, a fim de que ela não se considerasse um perigo para a sociedade. Criando laços de dependência e controle em relação ao outro, cria-se uma forma simbólica de manter hierarquias e controle social. O que muito tem a ver com uma frase célebre de E. P. Thompson: "O que de cima pode ser visto como benevolência, de baixo também pode ser visto como conquista".

Esse outro lado das instituições também se revela nos documentos oficiais, como é perceptível no Ofício $n^{\circ} 255$, carta de uma mãe ao governador da Província do Piauhy, em 04 de setembro de 1876, quando esta pede liberdade à filha Joana, menor de idade, em razão de ter sido transferida do ERSPA para a casa do Senhor Francisco Martins, "prestando serviços que repugnam a sua idade e não se conciliam com a educação que devia receber como pessoa livre que é". Em apelo desesperado da mãe, observa-se sua rejeição quanto à "proteção caritativa" direcionada à filha, em que menciona a função da instituição em garantir a proteção dos menores e não a piora de suas sortes, como no excerto abaixo:

Para tratar da criação e educação ninguém é tão competente como a sua
própria mãe, e a supp. (Joana), que não é inteiramente miserável, dispensa
a caridade que se lhe quer impor de um modo tão singular, pois tem meios
de criar sua filha, e está certa de que a ella se aproveitam mais os seus
desvellos do que essa oficiosidade estranha. [...] Para a criação e educação
destas (menores) existe na província um estabelecimento público, mantido
pelo Governo, a Colônia de São Pedro de Alcântara, onde devem ser
recolhidos, conforme se acha estabelecido na $2^{a}$ condição de contracto,
celebrado por Decreto $n^{\circ} 5.392$ de 10 de setembro de 1873 , e quando o
Governo impôs semelhante obrigação ao contractante d'aquela empresa, é
evidente que procurou garantir e não piorar a sorte das referidas menores.

Em seguida, o governador da Província do Piauhy encaminha ofício ao diretor do ERSPA à época, Dr. Francisco Parente, informando que as crianças e os jovens libertos nacionais ficariam em poder do Estado por um período de cinco anos, não podendo ser entregues às famílias antes do cumprimento deste prazo. Deste fato, como tantas ações políticas injustas e desumanas com em relação aos pobres e desvalidos de toda sorte, percebese que a história da infância é carregada de tragédia e marcada pelas mazelas da perversidade humana, nas mais diferentes nuanças, desde os portugueses que recrutavam meninos para trabalhar nas embarcações até o contexto da "nova escravidão". 


\section{Casa Pia de Lisboa: nascedouro da institucionalização da infância desvalida em Portugal}

Criada em 1780 pelo Intendente Geral da Polícia Diogo Inácio de Pina Manique, atendendo ao pedido da Rainha D. Maria I, a Casa Pia de Lisboa tem como respostas sociais: escola, casa de acolhimento temporário/unidade de emergência, residência de acolhimento, centro de apoio familiar e aconselhamento parental, lar residencial e lar de apoio.

A Casa Pia de Lisboa integra para além de quarenta e cinco (45) lares de acolhimento, dispersos pela cidade de Lisboa, dez Colégios: Pina-Manique (Belém); Nossa Senhora da Conceição (Rato); D. Maria Pia (Xabregas); Nuno Álvares (Ajuda); Santa Clara (Graça); Santa Catarina (São Bento); Instituto Jacob Rodrigues Pereira (para alunos surdos, no Restelo); S. Marçal (Príncipe Real); Instituto Aurélio da Costa Ferreira (para alunos surdoscegos e com deficiências mentais, em Alvalade); Escola Agrícola Francisco Margiochi (Quinta do Arrife, em Torres Vedras); Centro Educativo de Apoio Social (Almada); e Seis Centros de Acolhimento Temporário de Emergência para atender crianças e jovens em situação de perigo iminente, por quarenta e oito horas.

Esta instituição possui regime de internato, conforme matriz da Lei ${ }^{\circ}$ 147/99 - Lei de Protecção de Crianças e Jovens em Perigo -, configurando esta modalidade de acolhimento da instituição. Desde sua fundação, a Casa Pia tem o estatuto de instituto público e funciona sob a tutela do Ministério da Solidariedade, Emprego e Segurança Social.

\section{Quadro 1 - Instituições integradas à Casa Pia de Lisboa}

\begin{tabular}{|c|c|c|}
\hline Tipo de instituição & Missão & Onde \\
\hline $\begin{array}{l}\text { Casa de Acolhimento } \\
\text { Temporário/Unidade } \\
\text { Emergência I (crianças e jovens } \\
\text { dos 6-14 anos). }\end{array}$ & $\begin{array}{l}\text { Assegura uma resposta de acolhimento urgente e } \\
\text { transitório dirigida a crianças e jovens em } \\
\text { situação de perigo atual ou iminente, para a sua } \\
\text { vida ou integridade física, e para as quais não } \\
\text { existe resposta imediata. Exige a aplicação de } \\
\text { medida de promoção e proteção de acolhimento } \\
\text { em instituição. }\end{array}$ & CED Santa Catarina. \\
\hline $\begin{array}{l}\text { Residência de Acolhimento I } \\
\text { (crianças e jovens dos 6-14 anos) }\end{array}$ & $\begin{array}{l}\text { Assegura o acolhimento residencial de crianças e } \\
\text { jovens em situação de perigo, cujas circunstâncias } \\
\text { do caso aconselham um acolhimento superior a } 6 \\
\text { meses. Exige a aplicação de medida de promoção } \\
\text { e protecção de acolhimento em instituição. }\end{array}$ & $\begin{array}{l}\text { CED Santa Catarina. } \\
\text { CED Santa Clara. }\end{array}$ \\
\hline Centro de Apoio Familiar & Resposta que presta apoio especializado às & CED Santa Clara. \\
\hline
\end{tabular}

RIAEE - Revista Ibero-Americana de Estudos em Educação, Araraquara, v. 16, n. 3, p. 1774-1790, jul./set. 2021. e-ISSN: 1982-5587 


\begin{tabular}{|c|c|c|}
\hline Aconselhamento Parental. & $\begin{array}{l}\text { crianças e jovens que transitam das respostas de } \\
\text { acolhimento da CPL para meio natural de vida, e } \\
\text { que tem como objetivo assegurar a sua saída } \\
\text { sustentada, mediante o seu acompanhamento e } \\
\text { das respetivas famílias na comunidade, num } \\
\text { processo de autonomia progressiva. }\end{array}$ & \\
\hline $\begin{array}{l}\text { Lar Residencial I (crianças e jovens } \\
\text { dos 6-21 anos). }\end{array}$ & $\begin{array}{l}\text { Resposta desenvolvida em equipamento, } \\
\text { destinada ao alojamento de crianças e jovens } \\
\text { adultos surdocegos, que se encontram impedidos } \\
\text { temporária ou definitivamente de residir no seio } \\
\text { familiar ou que necessitem de frequentar } \\
\text { respostas educativas e/ou reabilitação da Casa Pia } \\
\text { de Lisboa e que não possam realizar deslocação } \\
\text { diária para a sua residência habitual. }\end{array}$ & $\begin{array}{lr}\text { CED António } \\
\text { Aurélio da Costa } \\
\text { Ferreira. }\end{array}$ \\
\hline $\begin{array}{l}\text { Lar de Apoio I (crianças e jovens } \\
\text { dos 6-21 anos). }\end{array}$ & $\begin{array}{l}\text { Resposta desenvolvida em equipamento destinada } \\
\text { a acolher crianças e jovens surdos, que } \\
\text { necessitem frequentar respostas educativas e/ou } \\
\text { formativas da casa Pia de Lisboa e que não } \\
\text { possam realizar deslocação diária para a sua } \\
\text { residência habitual. }\end{array}$ & $\begin{array}{l}\text { CED Jacob } \\
\text { Rodrigues Pereira. }\end{array}$ \\
\hline
\end{tabular}

Fonte: Elaborado pelas autoras - adaptado de Casa Pia de Lisboa (s/a $)^{4}$

No contexto de fundação das primeiras instituições de assistência e proteção à infância desvalida em Portugal, e nestas inclui-se a Casa Pia de Lisboa, como primeira delas e construída a pedido da Rainha D. Maria Pia (1847-1911) - conhecida como "anjo da caridade" -, Lisboa estava pejada de vagabundos, prostitutas e crianças abandonadas. Ainda não recomposta da devastação originada pelo terremoto de 1755 e do incêndio que se seguiu, a Lisboa da época era considerada uma cidade perigosa, pelo menos na ótica dos que detinham o poder.

Ao longo do século XIX, Portugal era considerado, no resto da Europa, um país atrasado e incompetente, considerando sua situação de instabilidade econômica percebida na maioria dos indicadores. Perto de $70 \%$ da população era analfabeta e entre os 143 mil operários fabris, havia 48 mil mulheres e 22 mil crianças. Com a maior parte da população trabalhando no setor agrícola, a importação de produtos alimentares provocou um enorme déficit na balança comercial, convencendo os líderes republicanos a criarem uma unidade

${ }^{4}$ Disponível em: http://www.casapia.pt/respostas_sociais.html. Acesso em: 10 out. 2020. 
nacional e salvaguardarem o império português se entrassem na Primeira Guerra Mundial ao lado dos Aliados (NEWITT, 2018).

Foi nesse contexto que muitas crianças foram abandonadas e/ou desprotegidas, criando a necessidade de medidas urgentes de institucionalização e controle sobre o caos social que se instaurava e refletia feiamente na organização da urbe. Sabe-se também que medidas religiosas de cunho caritativo e filantrópico estiveram à frente do poder público, na tentativa de "salvar" a alma destes pequeninos deserdados da sorte.

Em análise, a fonte documental Regulamento Interno para o Asylo de D. Maria Pia, uma das instituições do Instituto Casa Pia de Lisboa, no capítulo I, sobre Admissão e Exclusão das Crianças traz no artigo quinto informação sobre o ingresso e seleção destas crianças: "Haverá um livro de registro, onde serão inscriptas todas as crianças admitidas. Parág. 1': Esta inscripção será por termo, em que se mencionará o nome, edade, filiação, naturalidade e data da entrada das crianças, com referência à sessão e acta da admissão" (LISBOA, 1867, p. 6).

Com educação diferenciada para meninas e meninos, o estatuto desta preconiza exclusão das crianças que se tornarem incorrigíveis, ou que, sendo meninas, e tendo completado dez anos de idade, não mostrarem aproveitamento com o ensino e a educação. Os asilados recebiam formação religiosa, profissional e cívica, com intenso direcionamento moral e disciplinar. As crianças participavam de aulas de leitura, sistema legal de pesos e medidas, aritmética, escrita, história sagrada. No contraturno, os meninos estudavam leitura, aritmética e escrita, e as meninas faziam aulas de meia e costura.

De acordo com o art. 45 do Regulamento (Ibdem, 1867, p. 21), "não se lhes permitirá servilismo para com os mestres, condiscípulos ou protectores, mas só profundo respeito e veneração. [...] Far-se-lhes-há conceber que a honra, a virtude e o trabalho são de maior valor que a existência". Importante destacar que, nesta casa asilar que compõe o quadro de instituições geridas pela Casa Pia de Lisboa, segundo as fontes históricas consultadas, as crianças recebiam educação e trabalho compatíveis com suas capacidades intelectuais e físicas, sem quaisquer indícios de exploração.

Parecia haver preocupação institucional com as repercussões psíquicas do abandono, negligência e maus tratos em crianças e adolescentes. Mais recentemente, um autor português e médico psiquiatra da infầncia e da adolescência tem discutido esse tema, apoiando-se nos trabalhos clínicos de Anna Freud e Donald Winnicott, realizados na Inglaterra, nas décadas de 50 e 60, com crianças sobreviventes a traumatismos da Segunda Guerra Mundial. 
Não se sabe se havia estudos dessa natureza com as crianças institucionalizadas em Lisboa neste recorte temporal, mas os estatutos e regulamentos das instituições de infância desvalida, à época, revelam evidências de alguma preocupação com as consequências psíquicas, cognitivas e emocionais das crianças. Há algumas fontes que afirmam ser a instituição a mãe da criança. Ideia abordada por Makarenko (1998, p. 45) na década de 30, quando reflete sobre a "instituição reparadora do 'eu' infantil".

Abaixo, segue ilustração de crianças dos asilos e escolas de Lisboa no fim do século XIX, encontrada em exposição iconográfica na Coleção Moderna do Museu Calouste Gulbenkian, no mês de novembro de 2019.

Figura 3 - Crianças dos asilos e escolas de Lisboa em 1889

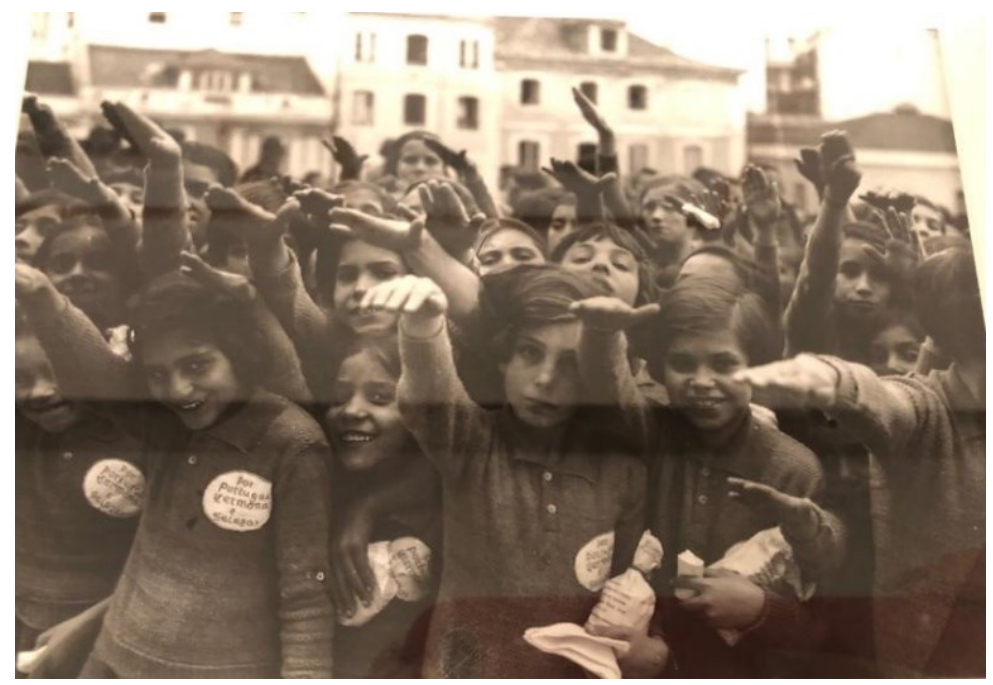

Fonte: Acervo das autoras

\section{Considerações finais}

Com a análise parcial das fontes e necessário cuidado para não cometer equívocos comuns neste tipo de pesquisa, muitos são os critérios e possibilidades de aproximação das realidades, assim como são da mesma forma inúmeros os aspectos a se considerar da análise das fontes. Primeiro, o processo de admissão e exclusão das crianças em cada uma das instituições que, a partir dos documentos observados, foram feitas de maneira diferente, tendo em vista o contexto histórico e as contingências econômicas e políticas em que Lisboa e Floriano estavam imersas.

Em seguida, percebe-se que as crianças das duas instituições possuem diferentes relações com o trabalho. No ERSPA, as crianças trabalham para pagar a moradia e devem jornadas de trabalho ao Estado, responsável por tutelá-las, em atividades agrícolas ou em 
serviços domésticos e rurais nas fazendas que estabeleciam acordo com o Governo da Província do Piauí à época. Em outra direção, na Casa Pia de Lisboa, as crianças trabalham com objetivos de disciplinamento e construção moral, para organizar o espaço que vivem (dormitórios, refeitórios), sem atrapalhar as aulas e demais atividades físicas e/ou profissionais. Nesta, as crianças são preparadas para o trabalho, como é o caso das meninas que aprendem um ofício (costura, serviços domésticos), ou mesmo dos meninos que precisam atender à expectativa institucional de revelar alguma aptidão profissional.

Parece não haver divergências quanto às idades das crianças para admissão nos dois contextos. Ao observar listas de alunos/as do ERSPA e da Casa Pia de Lisboa, ambos recebem crianças e adolescentes, até o início da vida adulta. Contudo, os critérios de admissões são diferentes, como já mencionados.

A Casa Pia de Lisboa, como modelo para muitas outras instituições de acolhimento à infância desvalida em Portugal e, consequentemente, para o Brasil, no século seguinte à sua fundação, revela-se uma referência de instituição de proteção e abrigo com fins educacionais, e não meramente assistenciais. Era comum que as primeiras instituições asilares fornecessem orientação e preparação para o trabalho, um direcionamento possível para que essa camada desassistida da sociedade tivesse um lugar digno, ainda que servil, ao alcançar a vida adulta. Essa preparação para o trabalho assumia características do desenvolvimento econômico do período, como é o caso das colônias agrícolas, em Portugal e no Brasil.

A propósito, a instituição de Floriano é uma escola agrícola, com função eminentemente prática a partir do próprio nome e função a que se designa; isto também significa influência portuguesa, quando no fim do século XVIII já havia em Lisboa Instituições Asilares com formação agrícola para meninos.

Outras considerações e constatações serão feitas após análise mais profunda e cuidadosa das fontes primárias. Essa incursão comparativa encontra-se em construção e ampliação de perspectivas, para outras articulações investigativas em curso.

\section{REFERÊNCIAS}

BEREDAY, G. Z. F. Comparative method in education. New York: Holt, Rinehart \& Winston, 1964.

BRASIL. Relatório apresentado à Assembleia Geral Legislativa na terceira sessão da décima quarta legislatura pelo ministro e secretário de Estado dos Negócios da Agricultura, Comércio e Obras Públicas, José Fernandes da Costa Pereira Júnior. Rio de Janeiro: Tipografia Americana, 1874.

RIAEE - Revista Ibero-Americana de Estudos em Educação, Araraquara, v. 16, n. 3, p. 1774-1790, jul./set. 2021. e-ISSN: 1982-5587 
BRAY, M.; ADAMSON, B.; MASON, M. (org.). Pesquisa em Educação Comparada: abordagens e métodos. Brasília: Liber Livro, 2015.

CAVAlCANTE, M. J. M. História educacional de Portugal: discurso, cronologia e comparação. Fortaleza: Edições UFC, 2008.

DEL PRIORE, M. (org.). História da criança no Brasil. São Paulo: Contexto, 1991.

FRANCO, L. C. Higienização e medicalização de crianças no Brasil: aproximações na História da relação Medicina - Saúde - Educação. 2018. Dissertação (Mestrado) Universidade Estadual de Maringá, Maringá, 2018.

GARRETT, A Portugal na balança da Europa. Londres: Livros Horizonte, 1830.

GARRETT, A. Comissão Executiva dos Centenários. In: CONGRESSO DO MUNDO PORTUGUÊS: ACTAS, MEMÓRIAS E COMUNICAÇÕES DO CONGRESSO NACIONAL DE CIÊNCIAS DA POPULAÇÃO, 1940, Porto. Actas do [...]. Porto: Imprensa Portuguesa, 1940. t. 1, v. 17.

GEREMEK, B. A piedade e a forca: história da miséria e da caridade na Europa. Lisboa: Terramar, 1995.

LIMA, F. S. História Administrativa do Brasil: organização e administração do Ministério da Agricultura no Império. Coord. Vicente Tapajós. Brasília: Funcep, 1988.

LISBOA. Regulamento interno para o asylo de D. Maria Pia. Lisboa: Imprensa da Universidade, 1867.

LISBOA. Relatórios e Contas das Casas de Asylo da Infância Desvalida de Lisboa. Lisboa: Imprensa Nacional, 1890.

NEWITT, M. Portuga na história da Europa e do mundo. 6. ed. Alfragide: Texto Ed., 2018.

NÓVOA, A. Tempos de escola no espaço Portugal-Brasil-Moçambique: dez digressões sobre um programa de investigação. In: NÓVOA, A.; SCHRIEWER, J. A difusão mundial da escola. Lisboa: Educa, 2000. p. 121-142.

NÓVOA, A. Modelos de análise de educação comparada: o campo e o mapa. In: NÓVOA, A. Educação comparada: rotas de além-mar. São Paulo: Xamã, 2009.

OLYMPIO, M. et al. Relatório da Instrução Pública. 1 jun. 1922.

PAVÃO, E. N. A. Balanço Histórico e Historiográfico da assistência à infância "desvalida" no Brasil. In: SIMPÓSIO NACIONAL DE HISTÓRIA, 26., 2011, São Paulo. Anais [...]. São Paulo: ANPUH, 2011.

QUEIROZ, T. Os literatos e a República: Clodoaldo Freitas, Higino Cunha e as tiranias do tempo. Teresina: Fundação Cultural Monsenhor Chaves, 1994. p. 29-39. 
RIZZINI, I. O século perdido: raízes históricas das políticas públicas para a infância no Brasil. Rio de Janeiro: Editora AMAIS, 1997.

VENÂNCIO, R. P. Maternidade Negada. In: DEL PRIORE, M. História das mulheres no Brasil. São Paulo: Contexto, 1997.

\section{Como referenciar este artigo}

CARVALHO, T. J. C. M.; HOLANDA, P. H. C. Institucionalização da infância desvalida em perspectiva comparada Lisboa/Portugal - Floriano/Piauí/Brasil (1834-1890). Revista IberoAmericana de Estudos em Educação, Araraquara, v. 16, n. 3, p. 1774-1790, jul./set. 2021. e-ISSN: 1982-5587. DOI: https://doi.org/10.21723/riaee.v16i3.13649

Submetido em: 04/05/2020

Revisões requeridas em: 13/01/2021

Aprovado em: 10/02/2021

Publicado em: 01/07/2021 